- News \& Views •

\title{
Comprehensive Marine Observing Experiment Based on High-Altitude Large Unmanned Aerial Vehicle (South China Sea Experiment 2020 of the "Petrel Project")
}

\author{
Xuefen ZHANG ${ }^{1}$, Liangxu $\mathrm{LI}^{*}{ }^{*}$, Rongkang YANG${ }^{1}$, Ran GUO ${ }^{1}$, Xia SUN ${ }^{1}$, Jianping $\mathrm{LUO}^{3}$, Hongbin $\mathrm{CHEN}^{4}$, \\ Daxin LIU1 ${ }^{1}$, Kebing TANG ${ }^{2}$, Wenwu PENG ${ }^{5}$, Xiaodong HAN 6 , Qiyun GUO ${ }^{1}$, Xiaoxia LI ${ }^{1}$, and Xikun FEI ${ }^{1}$ \\ ${ }^{1}$ Meteorological Observation Center of the China Meteorological Administration, Beijing 10081, China \\ ${ }^{2}$ AVIC Chengdou Aircraft Industry (Group) Co., Ltd., Chengdou 610092, China \\ ${ }^{3}$ Hainan Provincial Meteorological Bureau of the China Meteorological Administration, Hainan 570203, China \\ ${ }^{4}$ Key Laboratory of Middle Atmosphere and Global Environment Observation, Institute of Atmospheric Physics, \\ Chinese Academy of Sciences, Beijing 100029, China \\ ${ }^{5}$ Beijing Institute of Radio Measurement, China Aerospace Science and IndustryCorporation, Beijing 100854, China \\ ${ }^{6}$ AVIC Leihua Electric Technology Research Institute, Wuxi 421063, China
}

(Received 12 September 2020; revised 16 November 2020; accepted 3 December 2020)

\begin{abstract}
In collaboration with 12 other institutions, the Meteorological Observation Center of the China Meteorological Administration undertook a comprehensive marine observation experiment in the South China Sea using the Yilong-10 high-altitude large unmanned aerial vehicle (UAV). The Yilong-10 UAV carried a self-developed dropsonde system and a millimeter-wave cloud radar system. In addition, a solar-powered unmanned surface vessel and two drifting buoys were used. The experiment was further supported by an intelligent, reciprocating horizontal drifting radiosonde system that was deployed from the Sansha Meteorological Observing Station, with the intent of producing a stereoscopic observation over the South China Sea. Comprehensive three-dimensional observations were collected using the system from 31 July to 2 August, 2020. This information was used to investigate the formation and development processes of Typhoon Sinlaku (2020). The data contain measurements of 21 oceanic and meteorological parameters acquired by the five devices, along with video footage from the UAV. The data proved very helpful in determining the actual location and intensity of Typhoon Sinlaku (2020). The experiment demonstrates the feasibility of using a high-altitude, large UAV to fill in the gaps between operational meteorological observations of marine areas and typhoons near China, and marks a milestone for the use of such data for analyzing the structure and impact of a typhoon in the South China Sea. It also demonstrates the potential for establishing operational UAV meteorological observing systems in the future, and the assimilation of such data into numerical weather prediction models.
\end{abstract}

Key words: high-altitude large UAV, marine, typhoon, unmanned surface vessel, horizontal drifting radiosonde, drifting buoy

Citation: Zhang, X. F., and Coauthors, 2021: Comprehensive marine observing experiment based on high-altitude large Unmanned Aerial Vehicle (South China Sea Experiment 2020 of the "Petrel Project"). Adv. Atmos. Sci., 38(4), 531-537, https://doi.org/10.1007/s00376-020-0314-1.

\section{Introduction}

China is among the countries most severely affected by tropical cyclones (TCs). Annually, approximately seven - eight typhoons make landfall on the coast of China, causing economic losses of approximately 29.5 billion yuan (Chen et al., 2017). The lack of marine observational data represents a limiting factor regarding the improvement of typhoon forecasting skill. Since 1990, the error in typhoon track forecasting has decreased by approximately $50 \%$. This accomplishment is attributed to mainly two factors; first, to the improvements in mesoscale and synoptic-scale numerical forecasting, and second, to

\footnotetext{
* Corresponding author: Liangxu LI

Email: 1056682488@qq.com
} 
the advances in data assimilation technologies from mostly satellite observations. However, owing to the lack of high-resolution observations on TCs over the ocean, improvement in the accuracy of forecasting TC intensity has been limited during the same period.

Prior to meteorological satellite observations, records of typhoons covered only the periods of landfall and subsequent evolution. In recent decades, analysis of TC structure has been one of the most compelling problems in this field of TC research (Zhu et al., 2002). TCs spend most of their life cycles over the sea, and sudden changes in its strength or structure often occur at sea. However, owing to the lack of marine observational data with suitably high spatiotemporal resolutions, comprehensive understanding of the dynamics, thermal structure, and evolutionary processes of TCs remains lacking (Zhang et al., 2004; Halverson et al., 2006). The lack of understanding in these areas is one of the most important reasons for the limited improvement in TC intensity forecasting in recent years (Shu et al., 2011). Consequently, it is very important that suitable observations be obtained to improve TC forecasting skill.

By virtue of their maneuverability, flexibility, avoidance of risk to personnel, and other characteristics, unmanned aerial vehicles (UAVs) offer many advantages in comparison with other platforms for military, ecological, environmental and disaster surveys, and for taking meteorological measurements. With rapid advancement in UAV technology, applications of UAVs have become increasingly common in many fields and the prospects for further development are very broad. Aerial vehicle-based observations can be important for investigating marine typhoons (Bessho et al., 2006), obtaining information over terrestrial areas where construction of observing stations is difficult, and for verifying satellite observations (Lei, 2015). Therefore, airborne meteorological observations, especially those obtained using UAVs, may become indispensable sources of atmospheric data ( $\mathrm{Li}$ et al., 2009). The level of acquisition of airborne meteorological observations can be an important indicator of the meteorological observational capability of a country, as it can reflect the degree of modernization of a national meteorological service.

In addition to monitoring typhoons, UAVs can be used to observe sea surface conditions such as near-surface air temperature, humidity, pressure, and wind, as well as sea surface temperature and salinity, all of which are very important for analysis and forecasting of typhoons (Cao et al., 2019; Chen et al., 2019). Clearly, comprehensive three-dimensional observations of oceanic and atmospheric conditions using UAVs represents an important trend in the field of atmospheric measurement. For these reasons, the China Meteorological Administration (CMA) has launched the "Petrel Project", which will focus primarily on the comprehensive meteorological observing methods for typhoons and enhance the technical improvement of weather prediction and forecasting with the UAV platform, with the intent of establishing an operational mobile observing system for the CMA.

The Meteorological Observation Center (MOC) of the China Meteorological Administration has been working on selecting and deploying a large high-altitude UAV for field experiment data collection purposes since 2018. This effort is supported by the Ministry of Science and Technology of China and also through the Marine Meteorological Support Project. The MOC has selected the fixed-wing Yilong-10 UAV and has coordinated and carried out the installation of an airborne dropsonde system, a millimeter-wave cloud radar, and other instruments aboard the UAV for typhoon observation. The MOC also oversaw the development and engineering of other new remote observation platforms, including marine, unmanned surface vessels (USVs), drifting buoys, and intelligent reciprocating horizontal drifting radiosonde systems. Furthermore, they developed aircraft data receiving, processing, and command systems, as well as other related ground support systems. During June-August 2020, the first comprehensive three-dimensional field observation experiment over the South China Sea, the "South China Sea Experiment 2020" or "Petrel Project" for short, was undertaken by MOC in collaboration with 12 other institutions (including the AVIC Chengdu Aircraft Industry (Group) Co., Ltd., Hainan Provincial Meteorological Bureau, and the manufacturers of installed instruments). The 58-day experiment used the high-altitude large Yilong-10 UAV. The main tasks of the project included verification of the performance and overall adaptability of the UAV and its meteorological payload, as well as the development of the overall design of the field observation experiment. The tasks accomplished include the timely deployment of typhoon observation experiments over the South China Sea, successfully obtaining needed observational data, exercising procedures of observation-forecast interactions in field conditions, and exploring the feasibility for the establishment of a mobile, emergency operational observation system to process UAV-based observations.

\section{Experiment design and deployment}

\subsection{Experiment design and plan}

The area selected for South China Sea Experiment 2020, shown in Fig. 1, is a region where TCs occur frequently; it is in the central part of the South China Sea (northern boundary: Qionghai Boao, southern boundary: Xisha). Hainan Boao Airport $\left(19.15^{\circ} \mathrm{N}, 110.47^{\circ} \mathrm{E}\right)$ was selected as the base of operations for the Yilong-10 UAV flights up to $10 \mathrm{~km}$ in elevation. A solar-powered USV took controlled navigation observations in the zone of UAV operations. In addition, drifting sea surface observations were obtained by both buoy No. 20005, deployed $51.1 \mathrm{~km}$ southeast of the coast of the city of Wanning, and buoy No. 20006, deployed $103.3 \mathrm{~km}$ southeast of the coast of the town of Li'an in Lingshui County. An intelligent recip- 
rocating radiosonde system was deployed at Sansha Meteorological Observing Station. This system is capable of data collection during both ascent and descent, as well as when drifting horizontally in the stratosphere. These devices together provided comprehensive three-dimensional data collection within the experimental zone. The specific data collection routes and patterns are shown in Fig. 1.

\subsection{Aircraft platform and equipment involved in the experiment}

\subsubsection{UAV and meteorological payload}

The experiment used the high-altitude UAV Yilong-10, which is a fully autonomous platform (see Fig. 2). The vehicle's flight ceiling was $12 \mathrm{~km}$ and the experimental cruise altitude was $10 \mathrm{~km}$. Its total payload was more than $400 \mathrm{~kg}$ capable of speeds of up to $550 \mathrm{~km} \mathrm{~h}^{-1}$, and the flight duration was at least $5 \mathrm{~h}$.

The dropped sounding system used in the experiment was hung in pods underneath both wings of the UAV (Fig. 2). The system included the pod structure, radiosonde, signal receiver, radiosonde receiver antenna, GPS navigation antenna, radiosonde delivery mechanism/dropping mechanism, and a controller. Each pod can load up to 24 radiosondes that can acquire measurements with the following accuracy: temperature: $\pm 0.2^{\circ} \mathrm{C}$, relative humidity: $\pm 3 \%$, air pressure: $\pm 1 \mathrm{hPa}$, wind speed: $\pm 0.5 \mathrm{~m} \mathrm{~s}^{-1}$. The range of the receiver is up to $150 \mathrm{~km}$.

The millimeter-wave cloud radar was installed on the belly of the aircraft. The observation modes included the vertical fixed-point sensing mode and the vertical scanning mode, the upper limit of the observing distance is about $16 \mathrm{~km}$. The measured parameters included the reflectivity factor $(Z)$, radial velocity $(V \mathrm{r})$, and spectral width $(W)$. The radial resolution was $30 \mathrm{~m}$ and the angular resolution was $1.6^{\circ}$.

\subsubsection{Unmanned surface vessel}

The solar-powered USV was equipped with a control system, sensor system, and communication system. It observed tem-

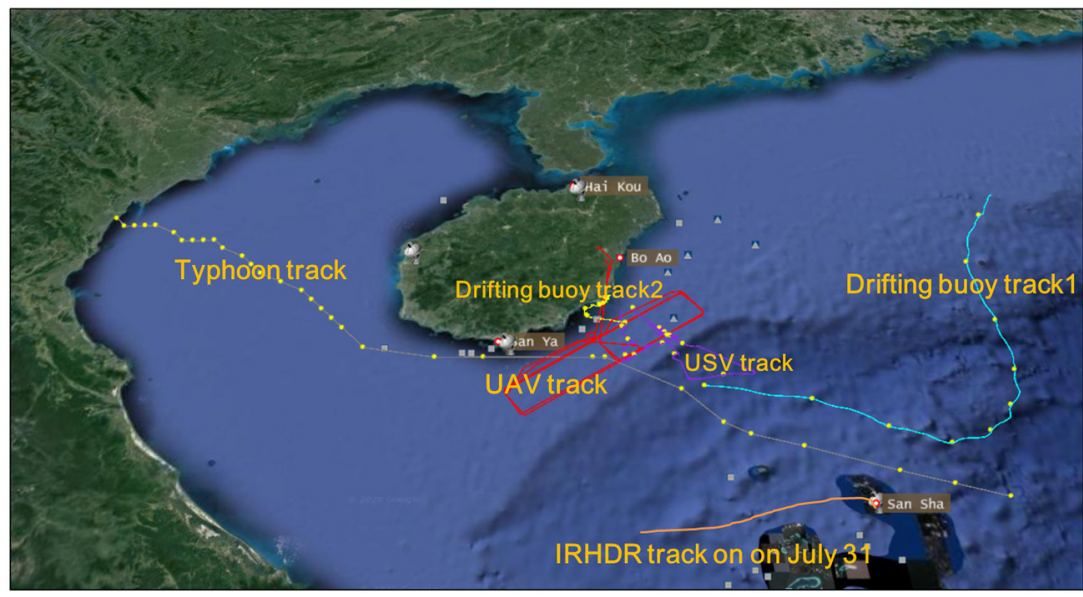

Fig. 1. Location of study area, layout of the comprehensive experiment, and trajectories of sea equipment in the South China Sea.

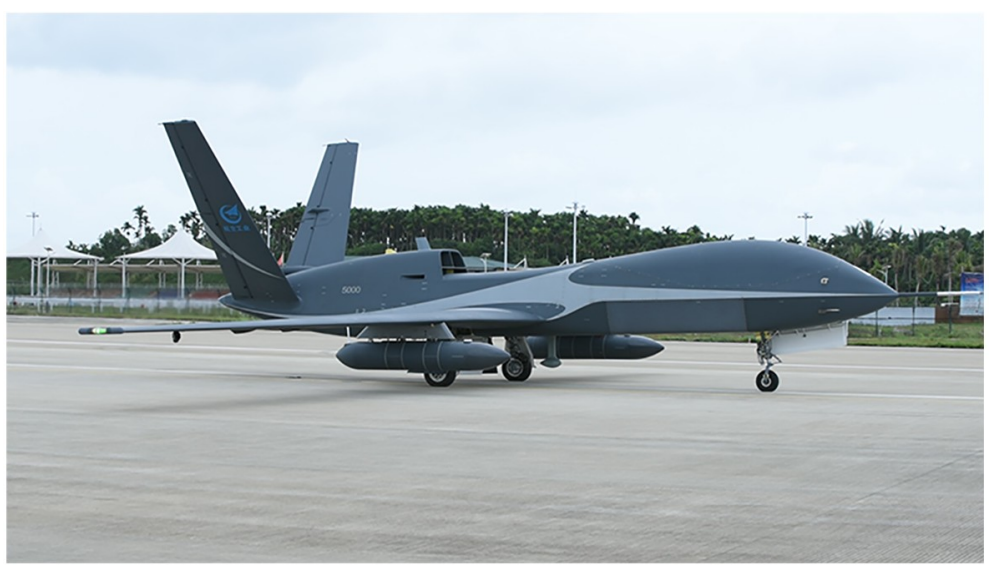

Fig. 2. The Yilong-10 UAV used in the experiment (Carried underneath the wings of the UAV are the dropsonde systems.). 
perature, air pressure, humidity, wind direction, and wind speed at $1.5 \mathrm{~m}$ above the sea surface, as well as sea surface temperature, salinity, shortwave radiation, and other parameters, while traveling at a speed of 3-5 knots. Observations were acquired at 1-min intervals. The observation modes included the navigation mode, positioning mode, and drifting mode, and the communication was conducted via the Beidou navigation and communication satellites.

\subsubsection{Drifting buoy}

The marine meteorological drifting buoys used were linked via the Beidou navigation and communication satellites. The observed variables included near-surface air temperature, air pressure, wind velocity as well as sea surface temperature and salinity. The observations were acquired at 10-min intervals.

\subsubsection{Intelligent reciprocating horizontal drifting radiosonde system}

The horizontally drifting radiosonde system was tracked using satellite navigation (see Fig. 3). It was comprised of carriers, payloads, and ground-based receiving equipment. The carriers included an outer balloon, an inner balloon, and parachutes. The outer and inner balloons acted as carriers during ascent and horizontal drift, respectively, while the parachute acted as the carrier during descent. The payloads included a separator and a radiosonde. The purpose of the separator was to separate the inner balloon and the parachute. The system can measure temperature, humidity, wind velocity, and air pressure, regardless of whether the radiosonde is ascending, descending, or drifting within the stratosphere.

\section{Observing experiment and data}

\subsection{Observing experiment}

In order to carry out typhoon observations, three UAV flights were conducted on 25 June, 2 July, and 12 July, 2020. These flights were used to validate and optimize the functional performance of the UAV, payload, and data transmission links. On July 19, a fourth flight obtained measurements of atmospheric temperature, humidity, wind direction, wind speed, air pressure profiles, and cloud data from the sea surface to $10 \mathrm{~km}$ altitude. Additionally, the flight recorded observations of the cloud structures such as cloud height and cloud thickness, as well as, microphysical characteristics (e.g. reflectivity factor) of the cloud system above the sea for the first time. During the 5 week period from June 25 to August 1 , eight intelligent, reciprocating horizontal drifting radiosondes (IRHDR) were released from the Xisha Upper-air Observatory (Fig. 4). The USV and two drifting buoys were deployed in the experiment region on 23 July 2020.

At 0700 UTC on 31 July 2020, a tropical disturbance was upgraded to a tropical depression by the Center Meteorological Observatory, and it was named "Sinlaku (2020)" at 0700 UTC on 1 August 2020 over the South China Sea. Notification of the tropical depression $\left(16.9^{\circ} \mathrm{N}, 113.4^{\circ} \mathrm{E}\right)$ was first issued at $0600 \mathrm{UTC}$ on July 31 . At that time, the USV and drifting buoys were observing continuously in the sea area affected by the low pressure system. At 1400 UTC on July 31 , an IRHDR was released, which found a substantial increase in humidity at the height of 6-8 km, attributable to the tropical

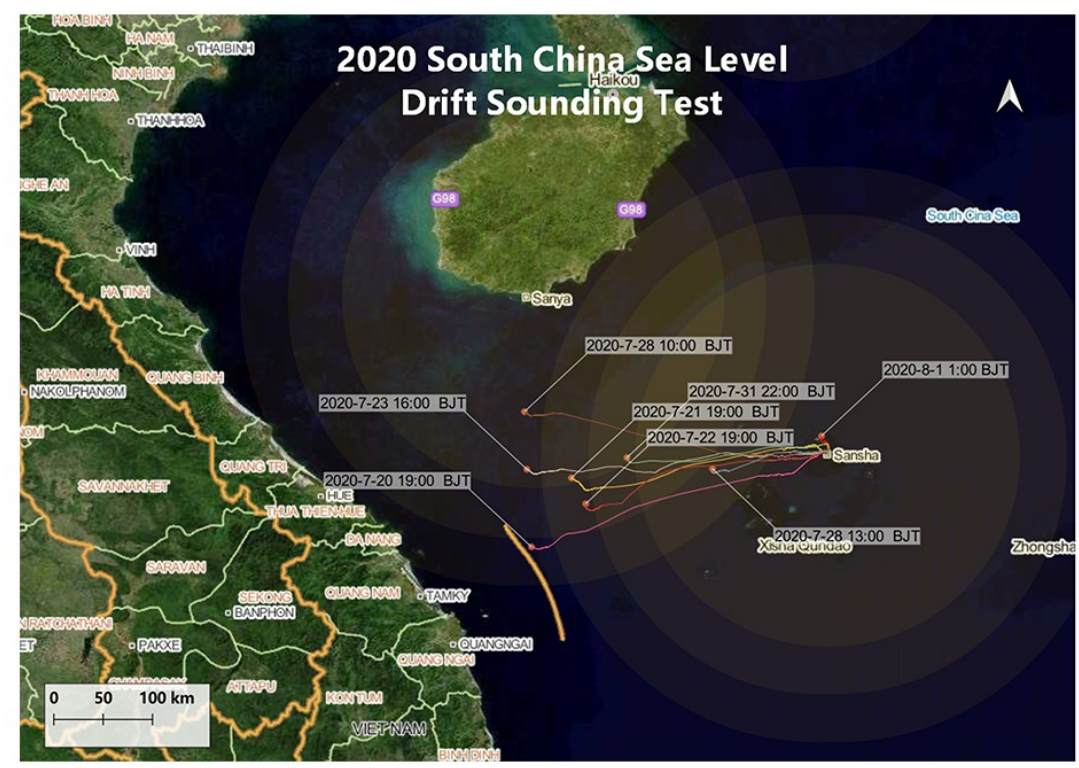

Fig. 3. Trajectories of intelligent reciprocating horizontal drifting radiosondes released during the South China Sea Experiment. 
depression. During 0100-0300 UTC on August 1, data acquired by the USV and buoys were provided in real time to the Typhoon Forecast Center of the China Meteorological Administration. Furthermore, at the request of forecasters, the experiment staff navigated the USV into a designated maritime area. The closest distance of the USV to the center of the low pressure was $2.4 \mathrm{~km}$. The measured sea level pressure was $996.8 \mathrm{hPa}$ (see Fig. 4), and the intensity of the typhoon center was $992 \mathrm{hPa}$, (i.e., "the typhoon intensity level"), according to the Central Meteorological Observatory of CMA. The drifting buoys also observed the change of pressure. At 0600 UTC on August 1, the Typhoon Forecast Center designated Senlake a named typhoon, and the observation systems on the sea surface played an important role in determining the location and intensity of the typhoon.

During the afternoon of 2 August, the UAV undertook a mission to observe the peripheral cloud system of Typhoon Sinlaku (2020). The UAV took off from Boao Airport and rose to a height of $10 \mathrm{~km}$. During the flight, it successfully obtained 30 sets of dropsonde profiles (Fig. 5) and millimeter-wave cloud radar data for nearly 80 min which completed the CT-type scanning of the peripheral cloud system of Typhoon Senlake, and transmitted the dropsonde profile data back to the ground-based command system in real time. Together with the instruments on UAV, the USV, drifting buoys, horizontal drifting radiosondes, and operational Fengyun meteorological satellites, a comprehensive data set was assembled that was then used to perform model verification and evaluation. Initial data analyses indicated that the South China Sea Experiment 2020 has achieved its pre-set goals, and a comprehensive three-dimensional data set on a typhoon using unique combinations of observing platforms was obtained for the first time; such systems can help fill operational gaps in observation of typhoons near China.
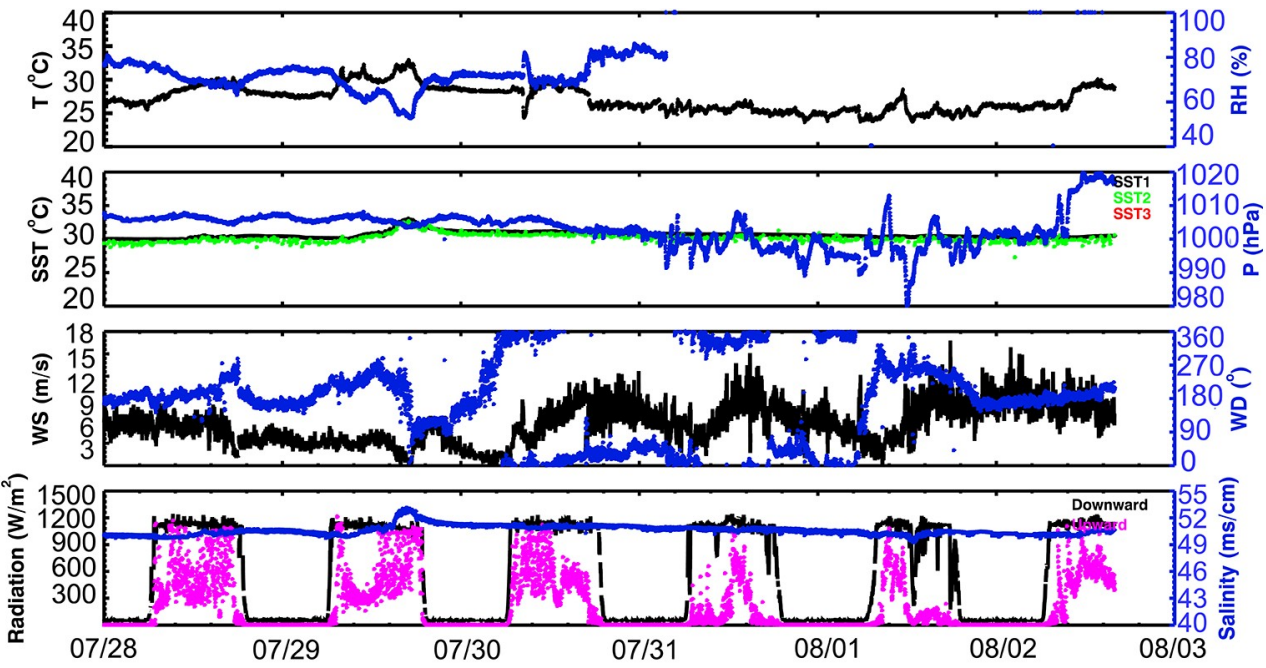

Fig. 4. Observational data of the USV (July 28, 2020 to August 2, 2020).

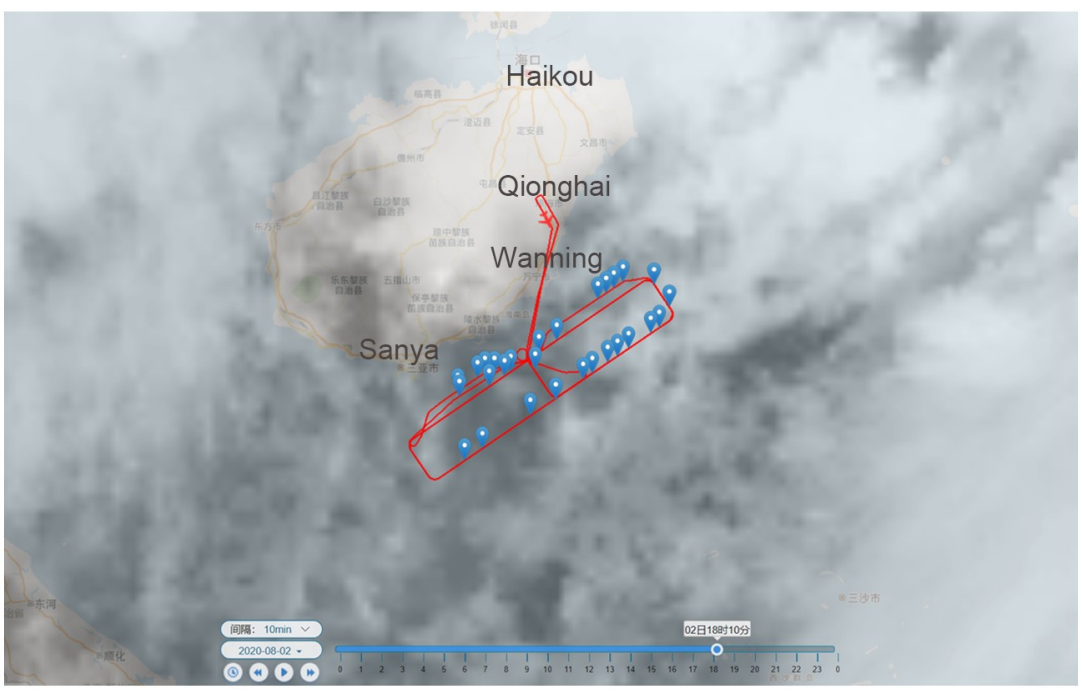

Fig. 5. Map showing positions of UAV dropped soundings (satellite cloud image of Himawari-8 has been added). 
Table 1. Specific details of the South China Sea Experiment 2020 data set.

\begin{tabular}{|c|c|c|c|c|}
\hline $\begin{array}{l}\text { Observation } \\
\text { equipment }\end{array}$ & Data time & Data size & Observation elements & $\begin{array}{c}\text { Data } \\
\text { interval }\end{array}$ \\
\hline $\begin{array}{l}\text { Dropping radio- } \\
\text { sonde system }\end{array}$ & July 19 , August 2 & 34 sets & $\begin{array}{l}\text { Temperature, relative humidity, air pressure, wind direc- } \\
\text { tion, wind speed, geopotential height }\end{array}$ & $1 \mathrm{~s}$ \\
\hline $\begin{array}{l}\text { Millimeterwave } \\
\text { cloud radar }\end{array}$ & July 19, August 2 & $110 \mathrm{~min}$ & Reflectivityfactor, speed, spectral width data & $250 \mathrm{~ms}$ \\
\hline $\begin{array}{l}\text { Unmanned sur- } \\
\text { face vessel }\end{array}$ & July 22 to August 2 & $315 \mathrm{~h}$ & $\begin{array}{l}\text { Sea surface temperature, relative humidity, wind speed, } \\
\text { wind direction, air pressure, shortwave radiation, sea } \\
\text { temperature, sea surface salinity }\end{array}$ & $1 \mathrm{~min}$ \\
\hline $\begin{array}{l}\text { Horizontaldrift } \\
\text { sounding }\end{array}$ & July 31 & 7 sets & $\begin{array}{l}\text { Temperature, relative humidity, air pressure, wind direc- } \\
\text { tion, wind speed, geopotential height }\end{array}$ & $1 \mathrm{~s}$ \\
\hline Drifting buoy & July 23 to August 2 & $\begin{array}{l}\text { No. } 20005,251 \mathrm{~h} ; \\
\quad \text { No. } 20006,245 \mathrm{~h}\end{array}$ & $\begin{array}{l}\text { Sea surface temperature, relative humidity, wind speed, } \\
\text { wind direction, air pressure, shortwave radiation, sea } \\
\text { temperature, sea surface salinity }\end{array}$ & $10 \mathrm{~min}$ \\
\hline $\begin{array}{l}\text { UAVforesight } \\
\text { camera data }\end{array}$ & August 2 & $240 \mathrm{~min}$ & $\begin{array}{l}\text { During the operation of the UAV, thetakeoff-flight-land- } \\
\text { ing video recorded by the foresight camera }\end{array}$ & $1 \mathrm{~s}$ \\
\hline
\end{tabular}

\subsection{Observational data}

The observational data set acquired during the South China Sea Experiment 2020 of the "Petrel Project" includes five types of 21 observational parameters and one UAV flying video file (which can be used for auxiliary analysis of data quality and cloud systems). The total size of the data set is $880 \mathrm{~Gb}$. Much of the data was obtained for the first time, for the given settings, and is therefore scientifically very valuable. The quality of the dropsonde and horizontal drifting soundings (except the horizontal drifting temperature data) exceeds the World Meteorological Organization standards. Analyses and evaluation of the data are ongoing. Specific information regarding the data is outlined in Table 1.

\section{Future work}

(1) Data analysis: Further quality control is needed for the experimental data sets, performance analysis and data evaluation, in order to carry out scientific research to both improve the observation experiment design and data collection strategies, and to gain scientific understanding of the observed systems.

(2) Optimization of instrumentation platforms: Goals are to include identification of problems with the UAV and other equipment platforms used in the experiment, improving the UAV platform and the payload instruments, and carrying out the remaining phases of the Petrel Project.

Acknowledgements. This project is supported by the Petrel Meteorological Observation Experiment Project of the China Meteorological Administration and the "Adaptive Improvement of New Observation Platform for Typhoon Observation (2018YFC1506401)" of the Ministry of Science and Technology. We wish to express our sincere gratitude to the Chengdu Aircraft Industry (Group) Co., Ltd., Hainan Meteorological Service, and all the other institutions and personnel that participated in this experiment.

\section{REFERENCES}

Bessho, K., M. DeMaria, and J. A. Knaff, 2006: Tropical cyclone wind retrievals from the Advanced Microwave Sounding Unit: Application to surface wind analysis. J. Appl. Meteorol. Climatol., 45(3), 399-415, https://doi.org/10.1175/JAM2352.1.

Cao, X. Z., X. X. Li, Y. Lei, and X. Wang, 2019: Typhoon observation and analysis of domestic marine meteorological drift buoy experiment. Meteorological Monthly, 45(10), 1457-1463, https://doi.org/10.7519/j.issn.1000-0526.2019.10.012. (in Chinese)

Chen, H. B., J. Li, S. Q. Ma, and S. Z. Hu, 2019: Progress of the marine meteorological observation technologies. Science \& Technology Review, 37(6), 91-97, https://doi.org/10.3981/j.issn.1000-7857.2019.06.012. (in Chinese)

Chen, W. F., Y. H. Duan, Y. Lu, J. Y. Fang, X. W. Shi, and F. M. Ren, 2017: Review on tropical cyclone risk assessment. Journal of Catastrophology, 32(4), 146-152, https://doi.org/10.3969/j.issn.1000-811X.2017.04.025. (in Chinese)

Halverson, J. B., J. Simpson, G. Heymsfield, H. Pierce, T. Hock, and L. Ritchie, 2006: Warm core structure of hurricane Erin diagnosed from high altitude Dropsondes during CAMEX-4. J. Atmos. Sci., 63(1), 309-324, https://doi.org/10.1175/JAS3596.1.

Lei, X. T., 2015: Progress of unmanned aerial vehicles and their application to detection of tropical cyclone. Advances in Earth Science, 30(2), 276-283, https://doi.org/10.11867/j.issn.1001-8166.2015.02.0276. (in Chinese)

Li, Y., S. Q. Ma, G. R. Wang, and Z. B. Sun, 2009: Preliminary analysis of Typhoon "Kalmaegi" observed by using unmanned aerial vehicle. Advances in Earth Science, 24(6), 675-679, https://doi.org/10.3321/j.issn:1001-8166.2009.06.014. (in Chinese)

Shu, S. J., Y. Wang, and J. J. Song, 2011: Observational analysis of the structure of Typhoon Haitang (0505) over the western North Pacific by using the GPS Dropsonde data. Acta Meteorologica Sinica, 69(6), 933-944, https://doi.org/10.11676/qxxb2011.081. (in 


\section{Chinese)}

Zhang, H., J. F. Chou, and C. J. Qiu, 2004: Assimilation analysis of Rammasun typhoon structure over Northwest Pacific using satellite data. Chinese Science Bulletin, 49(4), 389-395, https://doi.org/10.1007/BF02900323.

Zhu, P. J., M. Chen, Z. Y. Tao, and H. Q. Wang, 2002: Numerical simulation of typhoon Winnie(1997) after landfall Part II: Structure evolution analysis. Acta Meteorologica Sinica, 60(5), 560-567, https://doi.org/10.3321/j.issn:0577-6619.2002.05.006. (in Chinese) 